\title{
SABERES DOCENTES EM RUPTURA: UMA ANÁLISE DAS CONCEPÇÕES SOBRE A DOCÊNCIA DE PROFESSORES EM FORMAÇÃO
}

\author{
Cristiane MACHADO ${ }^{1}$ \\ Carla Helena FERNANDES ${ }^{2}$
}

RESUMO: Refletir sobre as concepções iniciais de futuros professores acerca da docência e do ensino, afirmando a importância dessas concepções para a construção dos saberes docentes e das práticas pedagógicas desse professor em formação é o objetivo deste texto. Destacam-se os resultados de pesquisa realizada com alunos do primeiro ano de um curso de Pedagogia acerca de suas concepções sobre a profissão e a prática docente. $\mathrm{O}$ texto ressalta que as concepções iniciais dos estudantes foram transformadas no processo de formação. Os que, inicialmente, apresentavam compreensão da profissão e da atuação profissional como arte (TARDIF, 2007), como ação que se realiza pela criatividade individual, somada às concepções relacionadas à vocação e altruísmo (BARROSO, 2006), transformaram essas concepções estabelecendo relação da profissão com prática profissional e técnica, apoiada em princípios científicos e pedagógicos. Buscando refletir sobre a formação profissional de professores, a partir dos resultados da pesquisa, o texto indica para ações de formação voltadas à análise e reflexão dos contextos e atividades locais dos professores como potencializadoras da ruptura com as concepções iniciais e da construção de novos e outros saberes docentes, bem como para as interlocuções entre os participantes da formação.

PALAVRAS-CHAVE: Concepções. Formação de professores. Saberes docentes. Interlocução.

\section{Introdução}

A educação escolar - compreendida como processos que envolvem a matrícula, permanência nas escolas e a aprendizagem/desenvolvimento de crianças e jovens - é um direito conquistado e garantido por meio de lutas políticas dos trabalhadores da educação e da sociedade em geral. É exercício de democracia e cidadania, como afirma Rios (2013), que objetiva a garantia do acesso ao conhecimento a todos, bem como autonomia na recriação desse conhecimento/saber.

Nesse quadro, o trabalho docente tem papel de importância no movimento de edificação de uma escola que realmente esteja voltada à construção da cidadania e democracia. A formação profissional dos professores para o contexto atual necessita adotar uma constante, permanente e radical reflexão sobre a prática, adotando uma perspectiva de uma formação profissional que considere 'formação' como

\footnotetext{
1 UNIVÁS - Universidade do Vale do Sapucaí. Pouso Alegre - MG - Brasil. 37550-000 cristiane13machado@yahoo.com.br.

${ }^{2}$ UNIVÁS - Universidade do Vale do Sapucaí. Pouso Alegre - MG - Brasil. 37550-000 carlahelenafernandes@yahoo.com.br.
} 
desenvolvimento em fluxo contínuo, iniciado antes mesmo do curso de formação, tendo como mote o exercício docente e a realidade dos diferentes contextos educacionais.

Assim, assumindo a perspectiva do desenvolvimento profissional e da própria formação como um continuum, e tendo como referência as ideias de Tardif (2007) e Baillauquès (2001), reafirmamos a relação entre concepções e prática docente e a importância de que as concepções dos professores (também os professores iniciantes e em formação) acerca da própria profissão sejam reconhecidas e refletidas também no próprio curso de formação inicial.

Tardif (2007) afirma que, na prática, as ações dos professores são dirigidas por modelos de ação que tem na sua base concepções acerca da docência e do ensino "[...] incorporadas na prática e que conferem uma inteligibilidade e um sentido à atividade educativa, oferecendo aos educadores significações, pontos de referência e orientações relativas às suas diversas ações”. (TARDIF, 2007, p.150). Para Baillauquès (2001), as concepções do professor - representações, como denomina a autora - são elaboradas a partir de discursos sociais, posições culturais e de hábitos, e também das experiências do professor enquanto aluno. Em função de suas características, envolve aspectos subjetivos e objetivos e agrega um espaço entre o interior e o exterior de cada sujeito. Para os autores, o trabalho sobre essas concepções poderia promover as ressignificações necessárias à demanda cotidiana do exercício da profissão docente.

Além dos autores cujas ideias servem de referência à construção deste texto, nossas considerações se referem também à pesquisa realizada com alunos do primeiro ano de um curso de Pedagogia, ao longo de um semestre letivo, que objetivou investigar as concepções desses alunos, futuros professores, acerca da docência e do ensino afirmando a importância do trabalho com essas concepções visando às rupturas necessárias à construção/reconstrução dos saberes docentese das práticas pedagógicas dos professores.

\section{Concepções, saberes docentes e formação profissional inicial}

Para Tardif (2007) a prática docente integra diferentes saberes com os quais os professores têm diferentes relações podendo-se, assim, definir o saber docente como “[...] saber plural, formado pelo amálgama, mais ou menos coerente, de saberes oriundos da formação profissional e de saberes disciplinares, curriculares e experienciais". (TARDIF, 2007, p.36). Se os três primeiros - saberes da formação profissional, disciplinares e 
curriculares - são produzidos pelas ciências da educação, transformados em programas curriculares e transmitidos pelos organismos formadores, já os saberes experienciais são aqueles produzidos pelos professores a partir de seu próprio trabalho e caracterizam-se pelo fato de se originarem da prática cotidiana da profissão. A produção dos saberes experienciais tem como base as múltiplas interações baseadas em situações concretas que não são "[...] passíveis de definições acabadas e que exigem improvisação e habilidade pessoal, bem como capacidade de enfrentamento de situações mais transitórias e variáveis". (TARDIF, 2007, p.49). Para o professor, essas situações são formativas e, além disso, estão relacionadas ao fato de que a prática docente se constitui em interação com outras pessoas/profissionais e saberes.

Em relação aos saberes experienciais, Tardif (2007, p.52) afirma que "[...] as certezas também são partilhadas e partilháveis nas relações com os pares[...]" e que é essa partilha que promove a contínua construção/reconstrução desses saberes entre a subjetividade e a realidade das escolas e salas de aula. $\mathrm{Na}$ interação com outros sujeitos (alunos e professores), os saberes da experiência podem ser retraduzidos, ou ressignificados, como anuncia Andrade (2007), que afirma a formação profissional como interlocução. Segundo essa autora, a possibilidade (outra) de diálogo da/na formação promove um deslocamento dos saberes inicialmente produzidos em uma ou outra instância.

Andrade (2007) reconhece nos "saberes científicos" da docência, em diálogo com os saberes e sujeitos da/na escola, atravessamentos que produzem furos no tecido desses saberes em relação ao seu campo de atividade ou esfera de produção.

\footnotetext{
Quando migram para o espaço de qualquer instância da formação continuada para ter entrada numa comunicação formadora, passam necessariamente por um processo de atravessamento, em que são permeados por outros saberes, trazidos da escola, pelos professores. Atravessados, não serão mais os mesmos: serão agora conhecimentos furados. Torna-se importante localizar e entender esses furos. Eles não desvalorizam o conhecimento da pesquisa, mas os ressignificam, ao colocarem-nos em diálogo com outros campos do saber, diferente do científico. Tais furos não são aleatórios: cada um desses furos destaca um ponto exato, resultado de buscas docentes. (ANDRADE, 2007, p.125-126).
}

O saber da formação atravessado pelo outro - outros sujeitos e outros saberes - é ressignificado pela própria busca da formação. Nas situações de formação, o reconhecimento da escola e dos professores como produtores de saberes e conhecimentos 
é fundamental para a interlocução que se estabelecerá. Para Tardif (2007), essa é uma relação construída em um jogo de reconhecimentos que no discurso, no diálogo, pode ser reconstruída.

Reconhecendo, portanto, a construção dos saberes docentes em fluxo contínuo entre a vida e a profissão e a partir das interlocuções e reflexões acerca da profissão, nossa atenção se volta à relação entre a aprendizagem da formação inicial, a realidade dos diferentes contextos educacionais e a bagagem de saberes deste futuro professor constituída das suas experiências pedagógicas e educacionais, também como aluno.

Nóvoa (1995) afirma a formação profissional como desenvolvimento pessoal, profissional e das organizações, o que só pode ser concebido em dimensões coletivas e individuais. A formação do professor se dá, portanto, num contexto de relações, o que consiste em concebê-la para além da dimensão técnica, bem como implica em reconhecer tanto um percurso pessoal de formação como o entrecruzar de histórias e pluralidades.

Retornando à Baillauquès (2001), deve-se considerar que os estudantes dos cursos de formação inicial já possuem alguns conhecimentos e crenças enraizadas e interiorizadas em relação à profissão e aos conteúdos da formação, fruto de suas experiências educacionais, sociais e culturais. A partir dessas concepções iniciais acerca do próprio ofício, os professores estruturam os conhecimentos da profissão e, por isso, essas representações relacionam-se à própria formação. Baillauquès (2001) concluiu que a própria ideia do que é ser "professor" e suas competências estão relacionadas às essas concepções pessoais. Nesse sentido, as pesquisas desenvolvidas por essa autora indicam queaspectos como vocação, paciência e autoridade, por exemplo,são indicados como competências de um professor com maior destaque do que para aspectos pedagógicos e cognitivos, específicos da atividade docente.

Nesse mesmo sentido, Tardif (2007) afirma que modelos de ação que estão na base da prática dos docentes concedem racionalidade à prática profissional que é expressa através das teorias que os professores empregam em suas ações. Em relação aos professores em formação e à própria formação profissional - temática abordada neste texto, os modelos de ação se apresentam na expressão de opiniões, nas primeiras práticas supervisionadas e nas escolhas de teorias (também daquelas estudadas nos cursos de formação) que convergem para esse modelo de ação. Para Tardif (2007, p.150): 
natureza de sua prática, representações essas que servem para defini-la, estruturá-la e orientá-la em situações de ação. Essas representações estão, portanto, incorporadas na prática; elas conferem uma inteligibilidade e um sentido à atividade educativa, oferecendo aos educadores significações, pontos de referência e orientações relativas às ações.

Tardif (2007, p.154, grifos nosso) caracteriza e define quatro principais modelos de ações, a saber:

1) educação enquanto arte; 2) educação enquanto técnica guiada por valores e 3) educação enquanto interação. As ações chamadas de tradicionais, baseadas em tradições pedagógicas, consistem em um quarto modelo de ação definido como 4) educação como atividades tradicionais.

A concepção de "educação enquanto arte" (TARDIF, 2007, grifo nosso), cuja origem relaciona-se à ideia de téchne dos antigos gregos, combina ação e criatividade, se diferenciando tanto da ciência (epistéme) como da prática (práxis). Nessa concepção e no modelo de ação que dá origem, o educador não é um cientista; sua ação não está voltada a"conhecer" (isto é, não requer um conhecimento/saber específico e prévio), mas está dirigida a um “fazer" em contexto específico e com indivíduos concretos. O saber necessário é construído no próprio fazer.

Significa que o professor, numa sala de aula, não possui uma ciência de sua própria ação, enquanto ele possa alimentar sua atividade com certos conhecimentos científicos. Ele age guiando-se por certas finalidades, e sua prática corresponde a uma espécie de mistura de talento pessoal, de intuição, de experiência, de hábito, de bom senso e de habilidades confirmadas pelo uso. (TARDIF, 2007, p.161).

Já na concepção de "educação enquanto técnica guiada por valores" (TARDIF, 2007, grifo nosso), a prática educativa é dirigida por princípios científicos e técnicos que fundamentam a prática, ou a justificam. Os professores devem fundamentar suas ações nesses princípios que precisam ser apropriados por eles.Nessa concepção as ações têm como referência normas e regras. Há também um saber específico - as ciências e as técnicas - que legitima a ação firmada e justificada como ato rigoroso, científico e ético, mas que, como toda escolha e opção, envolve tanto a objetividade como a subjetividade.

Quanto à "educação enquanto interação" (TARDIF, 2007, grifo nosso), este autor afirma que a atividade educativa diz respeito à comunicação e interação entre os sujeitos 
envolvidos. Nessa concepção ensinar é "[...] estabelecer relações e desenvolver com eles um processo de formação mediado pelas interações". (TARDIF, 2007, p.167). Ensinar é, nessa concepção, estar em relação; estabelecer interlocução.

Finalmente, o autor destaca as concepções e modelos de ação que tem como referência as práticas tradicionalmente desenvolvidas pelos professores. Na concepção da "educação enquanto atividades tradicionais" (TARDIF, 2007, grifo nosso), as práticas educativas são baseadas em costumes e maneiras de fazer que se mantém pelo uso tradicional das mesmas. Nessa concepção os professores atuam sem crítica e tendo em vista a tradição pedagógica.

Sobre essas concepç̃oes ou modelos de ação, nossos questionamentos vão no sentido de pensar como essas concepções, prévias e iniciais, podem interferir na atuação profissional e como podem ser aproveitadas na formação inicial formal. Nesse sentido, e buscando a formação em articulação com as demandas do exercício docente, questiona-se sobre que ações de formação devem ser realizadas levando em conta a realidade concreta de atuação do docente. Baillauquès (2001) afirma que, quando em contato com a realidade, isto é, na experiência do ofício e profissão, ocorre a ruptura com essas concepções, o que nos cursos de formação inicial pode ser propiciado por reflexões $\mathrm{da} / \mathrm{na} /$ sobre a prática.

A reflexão sobre o vivido pode promover reconstruções e ressignificações que enriquecerão e darão outra orientação ao professor e à sua prática. A reflexão sobre a prática é promotora da necessária ruptura com essas concepções, entendendo-se não como o seu abandono, mas como o esgarçar necessário e promotor de outros/novos saberes.

A reflexão do praticante sobre seu trabalho, que implica uma reflexão
sobre ele próprio, representa um engajamento crítico em sua
autoavaliação. As reflexões definem uma ação de retorno às
representações da prática e de si mesmo na prática [...] Após um
conhecimento mais preciso da realidade pessoal e profissional, as
reflexões suscitam remanejos, além da renúncia a imagens, valores,
crenças e conviç̧ões. (BAILLAUQUĖS, 2001, p.42).

Em Janeira (1972) encontramos uma interessante definição do termo ruptura para relacionarmos com o processo de construção de novos saberes e conhecimentos, próprios das trajetórias de formação. Para a autora a ruptura evidencia a separação de um 
fenômeno que, para efeito do nosso estudo, podemos compreender como o âmago das concepções sobre docência.

O termo ruptura é um daqueles que se podem aplicar em zonas muito diferentes e variadas. De tal modo que, quando o utilizamos, pretendemos transmitir uma ideia que, tocando a de superação, mutação, descontinuidade, revolução, corte, tem, no entanto, uma especificidade peculiar. [...] Devido a tal caráter, pode-se dizer, em síntese, que medeia entre os demais conceitos que assinalamos o conceito de ruptura: mais manifesto que aqueles, menos marcadamente global que este. Depois dessa breve resenha sobre a ruptura, parece-nos útil destacar o que essencialmente a define: fenômeno de separação brusca que cria uma interrupção com o fenômeno anterior, de tal modo que se cria entre eles uma separação-oposição. (JANEIRA, 1972, p.630).

A ruptura com crenças e convicções iniciais pode promover a reconstrução/construção dos saberes da docência enredando, nessa construção, pluralidade de outros saberes, o que pode ser mobilizado pela formação profissional se voltada aos contextos e atividades locais dos professores. Segundo Pérez-Gomes (2000, p.353) a formação profissional é responsável por “[...] provocar a reconstrução do conhecimento experiencial que os alunos adquirem em sua vida prévia e paralela à escola, mediante a utilização do conhecimento público como ferramenta conceitual de análise e contraste". Para Marcelo Garcia (1999), outro autor com quem dialogamos, as metas e finalidades na formação inicial de professores devem incluir "conhecimento, destreza, habilidade ou competências, e atitudes ou disposição", aspectos que se complementam e que envolvem as esferas cognitiva e afetiva da aprendizagem da docência.

Nesse sentido, o desafio da formação seria a elucidação das representações iniciais dos professores em formação e a organização de ações e projetos de formação que façam convergir essas representações iniciais dos professores em formação, o conhecimento teórico do curso de formação e o contexto vivo de trabalho dos professores.

\section{Concepções sobre a profissão e reflexões necessárias à formação: a pesquisa}

A pesquisa que aqui apresentamos é de cunho qualitativo, do tipo "avaliativo e decisório", cujo objetivo é "[...] descrever, documentar e/ou avaliar uma mudança planeada". (BOGDAN; BIKLEN, 1994, p.267). Foi realizada com estudantes do primeiro 
ano (segundo semestre) de um curso de Pedagogia em uma das disciplinas do programa curricular do curso cujo conteúdo está voltado às reflexões sobre a formação docente. A investigação foi desenvolvida no segundo semestre letivo de 2012 e buscou responder as seguintes questões:

1. Quais são as concepções iniciais dos estudantes acerca da docência e qual a relação dessas concepções iniciais com suas práticas docentes futuras?

2. Ao serem identificadas as concepções dos estudantes, como podem ser empregadas e trabalhadas na própria formação inicial visando tanto sua afirmação quanto sua transformação?

Serviram como instrumentos de investigação duas produções escritas dos estudantes, as quais nesse texto apresentamos a análise. A primeira delas desenvolvida com os estudantes nas primeiras aulas da disciplina, em agosto de 2012, contando com a participação na totalidade de estudantes, a saber, 40 estudantes; a segunda produção escrita foi realizada ao final do semestre letivo, em novembro de 2012, com a participação dos 33 estudantes que permaneceram no curso.

Para efeito desse texto os excertos apresentados serão indicados por PF, a saber, "professor em formação"; o número que acompanha refere-se a um dos quarenta/40 estudantes cujas escritas foram tomadas como objetos de investigação. Essas escritas foram numeradas aleatoriamente. Nas citações relativas à segunda produção escrita realizada pelos estudantes, os excertos serão apresentados indicados por PFII, a saber, "professor em formação - produção escrita II", mantendo-se o mesmo número relativo à primeira produção do estudante.

Quanto a essas produções escritas, no início do semestre, a professora responsável solicitou aos estudantes que escrevessem sobre a profissão de professor, cuja consigna era que escrevessem a partir do enunciado "ser professor é...". Ao final da disciplina, essa mesma consigna e produção foram repetidas. As escritas dos estudantes foram cotejadas com a ideia de modelos de ação de Tardif (2007). A análise de 1) as escritas iniciais dos estudantes e 2) do que produziram ao final da disciplina indicam transformações nas concepções dos alunos, professores em formação, e relação dessa mudança com o processo de formação, o que será apresentado e discutido na sequência desse texto.

\section{Concepções iniciais sobre a docência:}


1.1 "Educação enquanto arte": Das 40 produções analisadas no início da disciplina, 32 estudantes apresentaram concepções que se aproximam da definição de "educação enquanto arte" (TARDIF, 2007, p. 154, grifo nosso). Suas escritas transparecem concepções da prática educativa relacionadas a um fazer, ao desenvolvimento de uma ação, de uma prática. O excerto apresentado na sequência ilustra essa concepção: "Ser professor é ser artista, é reconhecer seus alunos como aprendizes. Professor é que professa, quem ensina algo e pratica a docência; é dominar a especificidade.” [PF3].

Nessa concepção, como afirma Tardif (2007), a ideia é de que as ações do professor são conduzidas pelo objetivo geral e universal da educação, a saber, educar e ensinar a todos. Este objetivo geral parece se sobrepor à saberes técnicos e específicos acerca da profissão. A prática profissional, nessa concepção, tem como referência uma mistura de talento (quase uma vocação) e intuição, que seria natural e pertinente à função, acrescida da experiência. Nesse caso a experiência teria relação com hábito e bom senso.

$\mathrm{Na}$ escrita dos estudantes emergiram termos e expressões que, em desdobramento à concepção de "educação enquanto arte" podemos relacionar também à ideia apresentada por Barroso (2006) acerca da imagem de professor como altruísta e missionário, ideia/concepção recorrente na afirmação de professores sobre seu trabalho e função profissional. Os excertos a seguir evidenciam isso:

Ser professor é ser parte fundamental da vida dos alunos, pois é ele que transmitirá conhecimentos e valores a eles. [...] É procurar ser modelo, buscar construir as bases que levarão o aluno a evoluir; é estar sempre ao lado do aluno, sendo sua segurança, investindo em suas capacidades [PF20].

Ser professor é prazeroso, pois é uma forma de contribuir para um mundo melhor, deixando um pouco de si para o outro. [...] É dar o melhor, buscar o amor; é fazer a diferença! [PF31]

Ser professor é gostar do que faz, saber transmitir seu conhecimento e sabedoria. [...] É saber respeitar, ensinar, saber compreender cada pessoa que te faz bem e fazer ao próximo. Saber ser educado para receber o respeito do aluno e até dos pais, para que possamos viver em sociedade cada qual com seus direitos e deveres [PF19].

Os excertos destacados evidenciam uma ideia messiânica da atuação do professor ao atribuir-lhe as tarefas de "estar sempre ao lado do aluno" [PF20], "contribuir para um mundo melhor" [PF31] e "saber compreender cada pessoa que te faz bem" [PF19], denotando outro significado para o papel do professor além do profissional, muito 
próximo de um "mensageiro divino" que conduz os alunos na vida como um todo, e não somente por entre a construção de saberes e conhecimento.

Nas escritas dos estudantes também podemos identificar expressões que, além de manifestar a ideia de professor como um "missionário" (BARROSO, 2006), fazem referência à individualidade e intimidade, como sugere a expressão "uma extensão da sua própria casa" no mesmo excerto.

Ser professor é mostrar o caminho, além de ensinar. É saber ouvir,sem pressa e sem preconceitos. É enxergar as habilidades onde não há nenhuma prova concreta de que elas existam. Investigar a curiosidadee alimentar os sonhos. É fazer o possível para que a sala de aula seja uma extensão da segurança de sua própria casa [PF40].

É perceptível, também, a aproximação com a ideia de maternagem, como também evidenciam os excertos que seguem.

Para ser professor é preciso, antes de tudo, gostar do que faz, acreditar em um mundo melhor, ter capacidade, ser paciente, gostar de estudar, saber ensinar, ter ética e ter conteúdo e ser um eterno pesquisador [PF2].

Ser professor é gostar do que faz e fazer bem feito; é ter dedicação, entusiasmo. [...] Ser professor é transmitir um pouco do que sabem com amor, porque eu acho que é uma das profissões que precisa ter uma dedicação muito grande [PF7].

As assertivas "gostar do que faz", "ser paciente" [PF2], "ter dedicação" e "com amor" [PF7] nos remetem ao universo da maternidade, mais do que à profissão docente. Ao contrário, entendemos que o exercício cotidiano do trabalho do professor é qualificado ou não a partir da construção, em formação, de saberes e práticas específicas, distantes e diferentes do instinto natural atribuído à maternidade. Enquanto o primeiro é uma profissão construída cultural e historicamente, o segundo é fundamentado no instinto de sobrevivência próprio da espécie humana.

A observação de que 32 estudantes escreveram acerca do ensino e da profissão como arte e vocação nos indica que para eles, e supostamente para muitos outros professores em formação, a escolha pela educação enquanto profissão está permeada pela ideia, também recorrente na sociedade em geral, de que essa escolha profissional, mais no que as demais profissões, está relacionada a um cumprimento de dever social, a uma escolha vocacional e subjetiva. Recorrendo mais uma vez à ideia de Tardif (2007) acerca dos saberes da docência, nossa compreensão sobre essa concepção que cerca a profissão e 
o exercício da docência indica a relação com as próprias características dos saberes da docência, que envolvem objetividade e subjetividade, construções coletivas e individuais (nesse caso constituídas também da bagagem social e cultural do professor), saberes sistematizados enquanto ciência bem como saberes em contínua construção que têm como base as experiências locais e particulares dos professores e futuros professores.

1.2 "Educação como técnica guiada por valores": Quanto a essa concepção que afirma uma ação relacionada pelo professor à princípios científicos e filosóficos, 05 estudantes afirmaram em seus escritos que a educação e a profissão de professor exigem saberes que estão acima da prática que a conduzem. Uma ideia escolanovista parece estar na base das escolhas desses estudantes, o que nos reporta à relações com suas experiências educacionais/pedagógicas anteriores. Além disso, termos como "pesquisa", "conhecimento", "ensino/aprendizagem"foram comuns às escritas dos estudantes de Pedagogia.

Ser professor é estar preparado para conduzir o aluno ao conhecimento, fazendo com que o aluno desperte o interesse pela aula. É ser capazde ensinar, buscar novos meios deensinar através da pesquisa quando os alunos têm alguma dificuldade de aprender." [PF13].

Ser professor é ser compromissado com o ensinar e não fazer distinção entre os alunos. É saber observar como os alunos estão se saindo na aprendizagem e procurar ajudar aqueles que têm mais dificuldade para aprender. Ter diálogo com os alunos, daroportunidades a eles para se expressarem;é ouvir suas ideias e experiências. E assim trabalharem juntos, tornando suas aulas mais produtivas [PF11].

Nas nossas análises, devemos observar que os estudantes cursavam o segundo semestre do curso de Pedagogia. Os excertos anterioresindicam relação com as ideias de alguns autores tradicionalmente estudados nos cursos de Pedagogia em disciplinas que compõem seu currículo,estudos esses que parecem ter sido perpassados pelos primeiros contatos com a realidade, por exemplo, quando os professores afirmam sobre alunos com dificuldade. O excerto apresentado abaixo também reforça essa relação. "É procurar buscar meios e métodos que possam colocar em prática da melhor forma possível. Éensinar e aprender com seus alunos, e pedir ajuda a quem já está no caminho há mais tempo." [PF24]. 
1.3 "Educação enquanto interação" (TARDIF, 2007, grifo nosso): Três/03 estudantes afirmaram essa concepção. Para eles, as trocas, as relações estabelecidas com os alunos devem ser o mote da docência e das práticas educativas.

Ser professor é uma troca de informações em que o aluno e o professor aprendem, trocam conhecimentos, se relacionam, vivem experiências novas a cada dia. O professor não é o mestre, o dono do saber. Ele também aprende com o aluno, principalmente com aqueles que vêm de outros estados, religiões diferentes, enfim culturas que não sejam iguais a dele [PF36].

Ser professor é algo bem mais complexo do que apenas ensinar; e sim ensinar, mas também é o ato de aprender. Ser professor é aprender a realidade de cada aluno individualmente; é ensinar a todos o mesmo conteúdo, mas às vezes de forma diferente [PF33].

Ser professor é poder estimular o aluno a construir seu próprio conhecimento; é poder dar a ele vários caminhos para se chegar até o objetivo final [PF32].

A concepção relativa à "educação como atividades tradicionais" não emergiu na escrita dos estudantes.

Do que foi relatado observamos que nos modelos de ação apresentados pelos estudantes do curso de Pedagogia estão presentes concepções que, para a maioria deles, se referem à compreensão da profissão e da atuação profissional enquanto arte (TARDIF, 2007), ação que se realiza pela criatividade individual, somada ainda às concepções relacionadas à vocação e altruísmo (BARROSO, 2006).

Cabe destacar ainda outra apreciação. $\mathrm{Na}$ análise das escritas dos estudantes constata-se que embora uma concepção apareça de forma mais clara (e essa concepção tenha sido indicadana pesquisa como concepção central às respostas dos estudantes) suas escritas indicam, em muitos aspectos, hibridez de duas ou mais concepções em relação às ideias que estão na base dos seus modelos definidores do papel e função do professor.

2. Concepções ao final da disciplina: rupturas

A disciplina foi organizada por meio da leitura de textos de educadores e pesquisadores que se dedicam à temática da formação docente. De modo específico e particular, as aulas tiveram como centro as discussões acerca da prática docente tendo como pano de fundo dessas discussões a vivência dos estudantes em diálogo com os autores estudados. $\mathrm{O}$ relato dos alunos nessas discussões indicava experiências anteriores ao curso de formação e/ou complementares a ele, como as atividades práticas 
desenvolvidas nas várias disciplinas. A reflexão sobre essas experiências e, em especial, as interlocuções promovidas nas aulas foram, assim como define Baillauquès (2001), importantes para as rupturas com as concepções iniciais, o que as escritas dos alunos evidenciaram. Participaram dessa produção final 33 estudantes.

2.1. Ruptura da concepção inicial de "educação enquanto arte": dos 32 estudantes que inicialmente haviam escrito sobre a docência tendo como referência concepção inicial de "educação enquanto arte" (TARDIF, 2007, grifo nosso), apenas 25 participaram dessa segunda produção escrita, sendo que:

- 2.1.1 estudantes mantiveram a mesma concepção, indicando para aspectos como vocação e afetividade também nessa escrita final (repetindo, ou reproduzindo, a escrita inicialsem outras alterações);

- 2.1.2 estudantes, porém, apresentaram mudanças quanto à concepção que está na base de suas escolhas, sendo que desses 06 deles apresentaram nessa produção final escrita que se referia à "educação enquanto técnica guiada por valores" (TARDIF, 2007, grifo nosso) e 07 estudantes escreveram sobre a "educação enquanto interação" (TARDIF, 2007, grifo nosso). A ruptura com a concepção inicialmente apresentada parece indicar para transformações que se deram no processo de formação. Sobre essas mudanças nos dedicamos na sequência do texto:

2.2 "Educação enquanto técnica guiada por valores": Em relação às produções dos 06 estudantes que indicaram em nessa produção aspectos relacionados a essa concepção, suas escritas indicam, no momento final do curso para a necessidade de saberes pedagógicos. Nossa leitura é que esse saber pedagógico é compreendido e assumido pelo estudante como um saber em construção, em ação, o que sugere, entre outros aspectos, a indicação da pesquisa como instrumento de saber sobre o aluno, a sala de aula e a docência, conforme mostram os excertos apresentados na sequência:

O professor deve ter domínio na organização, avaliação, planejamento etc. O professor é um eterno pesquisador, buscando conhecimento, aperfeiçoando [PFII31]

Ser professor é possuir as especificidades profissionais, ou seja, formação, planejamento e competências técnicas. Ser professor não é apenas transferir o conhecimento, mas sim possibilitar que o aluno o construa a seu modo. Ser professor é participar da gestão da escola, se envolver com o aluno. É buscar se qualificar e adquirir competência com a experiência. Também é nunca deixar de pesquisar para assim articular seus conhecimentos [PFII20]. 
Em alguns casos a produção dos estudantes indicava associação com a necessidade de reflexão e criticidade, o que sugere relação com, durante a disciplina, a leitura de autores que afirmam essa associação com a técnica profissional.

Ser professor é ser crítico, até com o modo de ser chamado, reivindicando sobre os direitos próprios[PFII19].

Ser professor é ter consciência de que somos os grandes responsáveis pela transformação social do meio em que atuamos [PFII37].

Os excertos apresentados anteriormente sugerem aspectos relativos às discussões teóricas, porém também apresentam indícios de saberes da experiência. De certa forma, a escolha pela concepção "educação enquanto técnica guiada por valores" apresentou como característica essa reconstrução/construção contínua de saberes a partir da dinâmica da escola e sala de aula.

2.3 "Educação enquanto interação": Dos 07 estudantes que a partir dos processos de reflexão e interlocução ocorridos durante a disciplina indicaram em sua escrita, nessa produção final, aspectos que podemos relacionar a "educação enquanto interação", apontamos em sua escrita aspectos que se referem à mediação entre o aluno, o professor (ou outro aluno) e os saberes.

\footnotetext{
Ser professor é proporcionar aos alunos oportunidades para que construam o seu próprio conhecimento; é ser o mediador do conhecimento. $O$ ato de ensinar é uma especificidade humana e então cabe ao professor essa tarefa nas escolas [PFII9].

O professor é o facilitador na construção do conhecimento. Assumir a identidade de professor é colocar em prática os ensinamentos. $O$ professor respeita o educando na construção de seu conhecimento, a aprender por si, fazendo, colocando em prática seu papel de mediador do conhecimento [PFII14]
}

Em relação às mudanças verificadas nas concepções dos professores em formaçãoque passaram a assumir a concepção de "educação enquanto interação" deve-se também considerar que as ações de formação desenvolvidas tinham como característica a reflexão crítica da realidade em interlocução. Assim, além de uma opção metodológica, as discussões levadas na disciplina acabaram por se transformar em conteúdos da própria formação, ou seja, o lugar da interação e da interlocução foi experienciado como uma prática de formação e de exercício docente. A partir da análise dos excertos das produções dos professores apresentados anteriormente reafirmamos a importância da 
presença do outro - outro aluno e outro/s professor/es, também daqueles sobre os quais se falou durante as aulas da disciplina.

Acerca dos demais estudantes que participaram da produção escrita ao final da disciplina, dos 05 que inicialmente, na primeira produção escrita, haviam afirmado em seus textos aspectos da concepção de "educação enquanto técnica guiada por valores" (TARDIF, 2007, grifo nosso) todos mantiveram a mesma concepção. Da mesma forma, todos os 03 estudantes que inicialmente escreveram acerca da docência como "educação enquanto interação" (TARDIF, 2007, grifo nosso) reafirmaram também essa mesma concepção.

Os quadros que seguem indicam os resultados quantitativos de cada uma das produções realizados com os estudantes:

\section{Quadro 1 - Primeira produção escrita: Concepções de professores em formação acerca da docência. Participação: 40 alunos.}

\begin{tabular}{|l|l|}
\hline Concepção & Incidência \\
\hline 1. "Educação enquanto arte" & 32 \\
\hline 2. "Educação enquanto técnica guiada por valores" & 05 \\
\hline 3. "Educação enquanto interação" & 03 \\
\hline 4. "Educação como atividades tradicionais" & 0 \\
\hline
\end{tabular}

Fonte: Elaboração própria.

\section{Quadro 2 - Produção escrita ao final da disciplina: Concepções de professores em formação acerca da docência. Participantes: 33 estudantes.}

\begin{tabular}{|l|l|}
\hline Concepção & Incidência \\
\hline 5. "Educação enquanto arte" & 12 \\
\hline 6. "Educação enquanto técnica guiada por valores" & 11 \\
\hline 7. "Educação enquanto interação" & 10 \\
\hline 8. "Educação como atividades tradicionais" & 0 \\
\hline
\end{tabular}

Fonte: Elaboração própria.

A análise anterior indica que houve mudanças nas concepções dos estudantes com as atividades da disciplina com significativa ampliação quanto ao reconhecimento da educação enquanto profissão e técnica. Essa análise nos indica sobre mudanças que ocorrem no processo de formação e que, consequentemente, interferem na atuação futura desse professor em formação, corroborando com a afirmação de Baillauquès (2001) sobre a possibilidade dos cursos de formação propiciarem a ruptura com as concepções arraigadas cultural e historicamente quando há o exercício da reflexão da/na/sobre a 
prática. As rupturas constatadas evidenciam, ainda, "a reconstrução do conhecimento". (PÉREZ-GOMES, 2000).

\section{Considerações finais}

Do que foi apresentado como resultado da pesquisa realizada, observamos que, inicialmente, nas concepções que emergiram das produções escritas iniciais de alunos de um curso de Pedagogia estavam presentes, em sua grande maioria, concepções que relacionavam a docência ao exercício individual, artesão, bem como à prática relacionada àamor e paciência. Porém, ao final da disciplina, os alunos apresentaram mudanças nessas concepções indicando para a docência como atividade técnica, profissional, baseada em preceitos científicos e pedagógicos, tendo essa análise referência nas ideias de Tardif (2007) acerca dos modelos de ação que estão na base da prática docente.

A partir da investigação realizada concluímos que as concepções iniciais dos estudantes foram alargadas no processo de formação e que a ruptura com as concepções iniciais está relacionada a esse alargamento. São os furos da/na formação promotores da reconstrução/construção dos saberes da docência a que se refere Andrade (2007) e que são, reafirmamos, frutos das reflexões e interlocuções das quais participa o futuro professor nos processos de formação.

Dos resultados da pesquisa, conclui-se que a formação inicial pode constituir-se em umespaço-tempo de rupturas através da reflexão de situações reais de ensino e aprendizagem, o que aconteceu durante a disciplina. Nesse sentido, as considerações a que chegamos referem-se a pensar a formação profissional do professor no atravessamento de diferentes saberes da docência (TARDIF, 2007), nos quais se incluem aqueles constituídos a partir das concepções que os professores em formação trazem de experiências educacionais relativas à própria formação inicial, bem como anteriores e/ou complementares a ela.

O trabalho com as concepções dos professores acerca da profissão durante o próprio curso de formação se refere a sentidos que precisam ser reafirmados ou revistos. A reflexão sobre os diferentes contextos de atuação profissional pode trazer para a formação a realidade vivida; o impacto dessa reflexão sobre os estudantes requer reflexões que sejam também mobilizadoras de outros/novos saberes. Nesse contexto, na pesquisa desenvolvida, as interlocuções entre os participantes da formação acerca de suas 
experiências como alunos e/ou docentes mostraram-se profícuas nas (trans)formações que se deram durante a disciplina.

A construção de educação realmente democrática, à serviço da aprendizagem escolar e do desenvolvimento de crianças e jovens brasileiros,envolve, entre outros aspectos, a reflexão sobre a docência. Nesse contexto, os conteúdos da formação e do exercício profissional devem estar inter-relacionados e, assim, a formação profissional assume o propósito de um olhar sobre a prática docente, no sentido de rever, olhar novamente e refletir para elaborar e reelaborar as rupturas necessárias.

\section{BREAK IN TEACHERS KNOWLEDGE: AN ANALYSIS OF THE CONCEPTIONS ON THE TEACHING OF TEACHERS IN TRAINING}

ABSTRACT: Reflecting on the initial conceptions of prospective teachers about teaching and education, affirming the importance of these concepts to the construction of teacher knowledge and pedagogical practices that teacher training is the objective of this text. Noteworthy are the results of research conducted with first year students of a Faculty of Education about his views on the profession and teaching practice. The text emphasizes that students' initial conceptions were transformed in the process of formation. Those who initially had understanding of the profession and the professional performance as art (TARDIF, 2007), as an action that takes place by individual creativity, combined with the concepts related to vocation and altruism (BARROSO, 2006), transformed these concepts establishing the relationship profession with practice and technique, based on scientific principles and teaching. Seeking to reflect on the training of teachers, from the results of the research, the text indicates actions for training focused on analysis and reflection of local contexts and activities of teachers as potentiating the initial break with the ideas and construction of new and others teaching knowledge, as well as the dialogues between the participants of the training.

KEYWORDS: Conceptions. Teacher training. Teacher knowledge. Dialogue.

\section{REFERÊNCIAS}

ANDRADE, L. T. Professores leitores e sua formação. Transformações discursivas de conhecimento e de saberes. Belo Horizonte: Autêntica, 2007.

BAILLAUQUĖS, S. Trabalho das representações na formação dos professores. In: PERRENOUD, P. et al. Formando professores profissionais. Quais estratégias? Quais competências? 2. ed. Porto Alegre: ARTMED, 2001. p.35-52.

BARROSO, J. A formação dos professores e a mudança organizacional das escolas. In: FERREIRA, N. S. C. (Org.). Formação continuada e gestão da educação. 2. ed. São Paulo: Cortez, 2006. p.117-143. 
BOGDAN, R., BIKLEN, S. Investigação qualitativa em educação. Porto: Porto Editora, 1994.

JANEIRA, A. L. Ruptura epistemológica, corte epistemológico e ciência. Análise Social, Lisboa, série 2, v.9, n.34, p.629-644, abr./jun., 1972. Disponível em:

<http://analisesocial.ics.ul.pt/documentos/1224260984P0tKE6sa0Ch37TP8.pdf>. Acesso em: 18 jan. 2013.

MARCELO GARCIA, C. Formação de professores para uma mudança educativa. Porto: Porto Editora, 1999.

NÓVOA, A. (Org.). Os professores e a sua formação. 2. ed. Lisboa: Dom Quixote, 1995.

PÉREZ-GOMES, A. I. A função e formação do professor/a no ensino para a compreensão: diferentes perspectivas. In: SACRISTÁN, J. G.; PÉREZ GÓMEZ, A. I. Compreender e transformar o ensino. 4. ed. Porto Alegre: ARTMED, 2000. p.353380 .

RIOS, T. A. Compreender e ensinar. Por uma docência da melhor qualidade. 4. ed. São Paulo: Cortez, 2003.

TARDIF, M. Saberes docentes e formação profissional. 8. ed. Petrópolis: Vozes, 2007. 